\title{
SISTEMATIZAÇÃO DA ASSISTÊNCIA DE ENFERMAGEM UMA INVENÇÃO BRASILEIRA?
}

\section{Rosimere Ferreira Santana ${ }^{1}$}

Corriqueiramente na prática, ensino e pesquisa tem-se o emprego da Sistematização da Assistência de Enfermagem como se referindo ao Processo de Enfermagem. Como no exemplo "aqui no hospital não temos a SAE", isso implicaria dizer que, conforme definido pela resolução COFEN 358 de 2009, não teria organização do "trabalho profissional quanto ao método, pessoal e instrumentos, tornando possível a operacionalização do processo de enfermagem", mas na verdade o que se quer dizer por traz disso seria "não temos implantado todas as fases do processo de enfermagem ou ainda não adotamos os sistemas de linguagem padronizadas - taxonomias". A confusão conceitual sobre o que seria SAE, Processo de Enfermagem e Taxonomias, e quando cada uma será empregada, ainda causas dúvidas seminais em profissionais experientes, e ainda limitam o avanço da profissão na prática clínica.

Se pensamos na definição de SAE, existe ainda o desejo de conceituar cada eixo, como por exemplo, o eixo método - descrito como o processo de enfermagem em si; portanto, o Processo de enfermagem estaria contido na SAE. Seria algo menor? Seria, portanto, um eixo da SAE?

E, porque, então, a distinção logo a seguir na mesma resolução, "Processo de Enfermagem é um instrumento metodológico que orienta o cuidado profissional de Enfermagem e a documentação da prática profissional" e ainda descreve detalhadamente as cinco fases do processo de enfermagem: Investigação, diagnóstico, planejamento, implementação e avaliação. Essas amplamente divulgadas e aceitas mundialmente, como sendo o modo de fazer o trabalho de enfermagem contemporâneo, o modo de emprego científico da enfermagem. Então, porque a criação da SAE no Brasil, se o Processo de enfermagem é em si o modelo do exercício profissional?

Destaque ao modo de documentar, também descrito na legislação, mas não detalhado, palco de diversas discussões, pois trata de outro polêmico tema da enfermagem mundial - à adoção de um sistema de linguagem padronizado único. No entanto, não obstante a taxonomia adotada, as etapas de registro e fluxo do trabalho são as mesmas mundialmente. Então porque no Brasil, a SAE sobressai em detrimento ao Processo de enfermagem?

Seria a condição histórica de instituição da profissão pautado historicamente na dicotomia lady-nurses administram e nurses cuidam. Seriam essas raízes históricas influenciando ainda hoje a dificuldade das enfermeiras centrarem suas atividades na execução do processo de enfermagem? Ou seja, no cuidado aos indivíduos, famílias e comunidades, na demonstração de resultados de sua ação, em detrimento de apoio aos demais profissionais.

Outro questionamento importante seria a distinção da Sistematização da Assistência de Enfermagem da área de Gestão em Enfermagem que trabalha na adoção de modelos organizacionais e gerenciais contemporâneos de gestão de pessoas, materiais, satisfação, indicadores, instrumentos, e qualidade do trabalho. Portanto, paira se realmente a definição SAE existe ou seria mais adequado defender a Gestão em enfermagem, se a gestão em enfermagem organiza o trabalho de enfermagem, termo esse reconhecido mundialmente, sem necessidade de redefinições, sem sobreposição e obscuridade.

\footnotetext{
${ }^{1}$ Enfermeira. Doutora em Enfermagem. Professora, Escola de Enfermagem Aurora de Afonso Costa/EEAAC/UFF. Niterói (RJ), Brasil.
} 
Contudo, ao decompor os eixos da Sistematização da Assistência de Enfermagem, compreende-se que seu conceito origina-se na Gestão em enfermagem, e que seu postulado na literatura e na Resolução acabaram por dar maior ênfase aos aspectos gerenciais que aos aspectos da própria aplicação do processo de enfermagem.

Em síntese, a SAE suporta a gestão em enfermagem. Dessa forma, organiza o trabalho profissional, possibilitando a organização do trabalho. No entanto, o Processo de Enfermagem carece de ser enfatizado no Brasil, como algo independente, como centro do cuidado de enfermagem, e não subentendido como associado a Sistematização da Assistência de Enfermagem, como uma invenção. Alicerçado no fato de que se não tenho pessoal, método ou instrumento eu não teria o Processo, e teríamos a própria enfermagem sem esses elementos? Isso tem sobremaneira impedido a implantação do processo de enfermagem na prática da enfermagem brasileira, com a ênfase a SAE, e ausência de luz ao Processo de enfermagem eixo norteador da profissão-ciência.

Descritores: Processos de Enfermagem; Diagnóstico de Enfermagem; Sistematização da Assistência de Enfermagem.

\section{REFERÊNCIAS}

1. Conselho Federal de Enfermagem (Brasil). Resolução COFEN n.358, de 15 de outubro de 2009. Dispõe sobre a sistematização da assistência de enfermagem e a implementação do processo de enfermagem em ambientes, públicos ou privados, em que ocorre o cuidado profissional de enfermagem, e dá outras providências [Internet]. Brasília, DF: COFEN; 2009 [citado em 28 dez 2019]. Disponível em: http://www.cofen.gov.br/resoluo-cofen3582009_4384.html

2. Fuly PSC, Leite JL, Lima SBS. Correntes de pensamento nacionais sobre sistematização da assistência de enfermagem. Rev Bras Enferm. [Internet]. dez 2008 [citado em 16 set de 2019]; 61(6):883-87. Disponível em:

http://www.scielo.br/scielo.php?script=sci_arttext\&pid=S0034-

71672008000600015\&lng=en. doi: http://dx.doi.org/10.1590/S003471672008000600015

3. Bellato R, Pasti MJ, Takeda E. Algumas reflexões sobre o método funcional no trabalho da enfermagem. Rev Latinoam Enferm. [Internet]. jan 1997 [citado em 7 dez 2019]; 5(1):75-81. Disponível em: http://www.scielo.br/pdf/rlae/v5n1/v5n1a09.pdf. doi: http://dx.doi.org/10.1590/S0104-11691997000100009

4. Peres AM, Ciampone MHT. Gerência e competências gerais do enfermeiro. Texto \& Contexto Enferm. [Internet]. 2006 [citado em 28 dez 2019]; 15(3):492-99. Disponível em: http://www.scielo.br/pdf/tce/v15n3/v15n3a15.pdf. doi:

http://dx.doi.org/10.1590/S0104-07072006000300015 